\title{
On Non-Progressive Verbs: a Corpora-Based Analysis
}

\author{
Nam-Kil Kang \\ Prof. \\ Department of English Language \\ Far East University \\ Daehak-gil, Gamgok-myeon, Eumseong-gun \\ South Korea
}

\begin{abstract}
The ultimate goal of this article is to provide a detailed frequency analysis of major stative verbs, major sensation verbs, and major mental activity verbs within the Corpus of Contemporary American English (COCA), the British National Corpus (BNC), the Corpus of Historical American English (COHA), and the Time Magazine Corpus (TMC) and to provide clues as to why non-progressive verbs occur in the progressive and why they show differences in the use of the progressive. In this article, we argue, in support of Cowan (2010) and Palmer (1987) that non-progressive verbs can occur in the progressive. Cowan (2010) contends that a certain action becomes more emotional, intense, and vivid if a stative verb appears in the present progressive instead of the simple present. Also, he claims that non-progressive verbs occur in the progressive when the speaker wishes to express the idea of evolving process. Palmer (1987) maintains that stative verbs are used for limited duration and that the progressive is unlikely unless a change of state is indicated. With respect to the frequency of progressive statives, a major point to note is that the reason why please has the highest frequency among the stative verbs contain, belong, and please may be that it has the plus-feature in volition which contain and belong lack. A further point to note is that the reason why feel obtains the highest frequency among the sensation verbs smell, taste, and feel is that smell and taste have the plus-features in volition and dynamism, whereas feel has the plus-features in duration, volition, and change. The data in this article strongly suggest that the reason why the type forget is used more frequently than smell and taste may be that forget has the plus-features in volition, duration, and change, whereas smell and taste have the plus-features in volition and dynamism. These observations lead to the hypothesis that duration, volition, change, and dynamism are factors which trigger progressives.
\end{abstract}

Keywords: progressive, four factors, corpus, COCA, BNC, COHA, TMC

\section{Introduction}

"Corpora are large machine-readable compilations of authentic texts. They can be general or specialized, depending on what kinds of texts are included in the corpus" (Cotos 2017: 249). The Corpus of Contemporary American English (COCA), the British National Corpus (BNC), the Corpus of Historical American English (COHA), and the Time Magazine Corpus (TMC) have recently attracted considerable attention from researchers since they are specialized for both spoken and written English. The ultimate goal of our research is to demonstrate that the so-called non-progressives such as major stative verbs, major sensation verbs, and major mental activity verbs can be used as the progressive, which is captured within the COCA, BNC, COHA, and TMC and to provide clues as to why non-progressive verbs occur in the progressive and why they show substantial differences in the use of the progressive. The organization of this article is as follows. Section 2 and section 3 provide background discussion for the remainder of this article. Section 4.1 is focused on a frequency analysis of major stative verbs, major sensation verbs, and major mental activity verbs which occur in the progressive in the COCA. To begin with, we offer rational explanations as to why non-progressive verbs occur in the progressive. In this section, we argue that the reason why the stative verb please obtains the highest frequency among contain, belong, and please may be because it has a connotation of volition which the other statives lack. We further argue that the reason why the sensation verb feel has the highest frequency among smell, taste, and feel is that the sensation verbs smell and taste have the minus-feature in duration, whereas the sensation verb feel has the plus-feature in duration which is supposed to be an important factor that induces progressives. 
Section 4.2 is devoted to analyzing the frequency of major stative verbs, major sensation verbs, and mental activity verbs used as the progressive in the BNC. We argue in this section that language is the vehicle of thought and that American people are emotional people in that they want a certain action to become more emotional, intense and vivid in both spoken and fiction genres. On the other hand, British people are more or less conservative in their use of progressive statives in view of the fact that they use fewer progressive statives than American people. We maintain in this section that the reason why the frequency of the fiction genre in both COCA and BNC is higher than that of the other genres is that writers in novels may use the strategy that a certain action can become more emotional, intense, and vivid. Also, we contend that one of the reasons why the sensation verb feel is used much more frequently than the sensation verbs smell and taste may be that it has a connotation of duration which smell and taste lack. We argue in this section that mental activity verbs mainly occur in the progressive to provide an informal polite tone and to hedge or soften a definitive opinion. In section 4.3, our discussion centers on analyzing the frequency of nine non-progressive verbs which occur in the progressive in the COHA. In this section, we maintain that the sensation verb feel has connotations of change, duration, and volition which may trigger the progressive, whereas the stative verbs contain and belong have the plus-feature in only duration but the minus-features in change, dynamism, and volition, which may result in the extremely low frequency. Similarly, we maintain that the reason why the type forget is used more frequently than smell and taste may be that forget has the plus-features in volition, duration, and change, whereas smell and taste have the plusfeatures in volition and dynamism. In section 4.4, we provide a frequency analysis of nine non-progressive verbs used as the progressive in the TMC. We contend that the most preferable type for educated American people among the nine non-progressive verbs from the 1920s to the 2000s was the type feel. We further contend that among three types of non-progressive verbs, the sensation verbs were the most preferred by educated American people, followed by the mental activity verbs, and the stative verbs, in that order.

\section{Non-Progressive Verbs}

It is a commonly observed phenomenon that many verbs refer not to an activity but to a state or condition. Palmer (1987) contends that the sense of duration is an integral part of the lexical meaning of the verb. For example, languages commonly allow speakers to describe a situation as static or unchanging for its duration. Such states are described in the following examples:

(1) contain: It contains sugar.

belong: It belongs to me.

matter: It doesn't matter.

deserve: He deserves something better than that.

consist: It consists of little but water and colouring.

please: It pleases me no end.

depend: It depends on what you mean.

own: I own my own house.

(Palmer 1987: 71)

It is standardly assumed that as Saeed (2009) points out, these verbs allow the speaker to view a situation as a steady state, with no internal phases or changes. Moreover, the speaker does not overtly focus on the beginning or end of the state. Saeed (2009) maintains that even if the speaker uses a stative verb in the past, no attention is directed to the end of the state:

(2) Mary loved to drive sports cars.

(Saeed 2009: 109)

As pointed out by Saeed (2009) and Quirk \& Greenbaum (1993), stative verbs display some grammatical differences from dynamic verbs. For example, the progressive in English can be used of dynamic situations, as alluded to in (3a) below:

(3) a. I am learning Swahili.

b. *I am knowing Swahili.

(Saeed 2009: 120) 
As noted by Vlach (1981), this is possibly due to the fact that learn is used with dynamic situations rather than states and has connotations of dynamism and change. As indicated in (3b), on the other hand, the stative verb know rarely appears in the progressive aspect since it has a steady state.

Private verbs are those that refer to states or activities that the speaker alone is aware of. As plausibly argued by Palmer (1987), these have two kinds, those that refer to sensations and those that refer to mental activities, which commonly occur with non-progressive verbs. Verbs referring to sensations are as follows:

(4) see: I see my brother over there.

smell: I smell something burning.

hear: I hear music.

taste: I taste salt in this.

feel: I feel something hard.

(Palmer 1987: 73)

Verbs referring to mental activities are as follows:

(5) think: I think that's mine.

imagine: I imagine he'll be there.

hope: I hope it's true.

plan: I plan to go to London tomorrow.

forget: I forget what you said.

believe: I believe that it's true.

(Palmer 1987: 73)

As illustrated in (4) and (5), verbs referring to sensations and verbs referring to mental activities have the common characteristic that both normally do not occur in the progressive.

\section{Methodology}

The ultimate goal of this article is to provide clues as to why non-progressive verbs take progressive forms and why they show differences in functioning as the progressive. Thus, a specific empirical objective of this article is to provide a frequency analysis of the present and past progressive of major stative verbs, major sensation verbs, and major mental activity verbs which are the symbols of non-progressive verbs. As appropriate tools to achieve our goal, we adopt the Corpus of Contemporary American English, the British National Corpus, the Corpus of Historical American English, and the Time Magazine Corpus. Our discussion within these corpora centers on answering the following questions: Which type is the most frequently used one as the progressive? What is the reason for it? Why do non-progressive verbs occur in the progressive? Why do non-progressive verbs show differences in the use of the progressive? What does the frequency of the COCA, BNC, COHA, and TMC stand for? What are the differences between the results of the COCA and those of the BNC? What are the traits of educated American people in the use of the progressive?

\section{Results and Discussion}

\subsection{A Frequency Analysis of Non-progressive Verbs (COCA)}

Table 1 shows the frequency of three major stative verbs used as the progressive in the COCA (1990-2012):

Table 1 Genre Frequency of Three Major Stative Verbs Used as the Progressive (COCA)

\begin{tabular}{|l|l|l|l|l|l|l|}
\hline Context & Spoken & Fiction & Magazine & Newspaper & Academic & Total \\
\hline contain & 9 & 1 & 1 & 5 & 2 & 18 \\
\hline belong & 7 & 2 & 2 & 2 & 0 & 13 \\
\hline please & 16 & 40 & 41 & 16 & 27 & 140 \\
\hline
\end{tabular}

A major question that must be addressed here is "which type is the most frequently used one as the progressive in all genres of the three types?" Table 1 clearly illustrates the fact that the type please is the most frequently used one in all genres of the three types. It is noteworthy that as alluded to in Table 1, stative verbs which are the symbols of non-progressive verbs can be used as the progressive and that the type please is the most widely used as the progressive. 
That is to say, Table 1generates the significant fact that non-progressive verbs can take progressive forms, despite the well-known fact that they are not supposed to be used as the progressive. One major point of the token analysis of the stative verb please is that the magazine genre has the highest frequency and the highest proportion, but the spoken and newspaper genres have the lowest frequency and the lowest proportion. Now an important question to be asked here is "why are stative verbs used as the progressive?" Cowan (2010) contends that "the action becomes more emotional, intense, and vivid if a stative verb appears in the present progressive instead of the simple present" (Cowan (2010: 363). Clearly,the present progressive expresses much more emotion than the simple present:

(6) a. This operation is really costing a lot of money.

b. This operation costs a lot of money.

(Cowan 2010: 363)

Palmer (1987: 72) points out that there are two notable uses of stative verbs in the progressive. Note that the progressive is used to indicate activity in a limited period of time (Twaddel 1960: 8). First, as plausibly argued by Palmer (1987: 72), in (7), the present progressive of stative verbs is used for limited duration:

(7) a. He's looking better since his operation.

b. I'm feeling quite well now.

(Palmer 1987: 72)

Also, it is significant to note that with verbs of stance as illustrated in (8) and (9), the distinction between the progressive and non-progressive is even more specific. Simply put, the former indicates a temporary state, whereas the latter a permanent state:

(8) a. We live in London.

b. We're living in London.

(9) a. The statue stands in the middle of the square.

b. The boy is standing in the middle of the room.

(Palmer 1987: 72)

Second, Palmer (1987: 72) maintains that the progressive is unlikely unless a change of state is indicated:

(10) a. He's looking more and more like his father.

b. It's mattering less and less now.

c. It's tasting nastier and nastier.

(Palmer 1987: 72)

Also, Cowan (2010) stresses that "stative appearance verbs such as appear, resemble, and seem, and stative cognitive verbs such as believe, know, mean, and understand occur in the progressive aspects when the speaker wishes to express the idea of evolving process" (Cowan (2010: 364). Cowan (2010: 364) shows that in the case of (11a), (11b), (11c), and (11d), the direction of the process is indicated by expressions such as more and more, worse and worse, faster and faster, and so on.

(11) a. The baby is resembling his father more and more every day.

b. He's looking worse and worse by the minute.

c. That example is sounding less and less acceptable with each repetition.

d. I am understanding more and more about the English tense-aspect system.

(Cowan 2010: 364)

The outcome of our discussion in this section is summarized by the following table:

Table 2 Non-progressive Verbs used as the Progressive

\begin{tabular}{|l|l|l|l|}
\hline Scholar & Verb Types & Progressive & Meaning \\
\hline Palmer (1987) & Non-progressive verbs & Yes & Limited duration \\
\hline Palmer (1987) & Non-progressive verbs & Yes & A change of state \\
\hline Cowan (2010) & Non-progressive verbs & Yes & Emotional, intense, and vivid \\
\hline Cowan (2010) & Non-progressive verbs & Yes & Evolving process \\
\hline
\end{tabular}


Now a question that naturally arises here is "why does the stative verb please have the highest frequency among the three types?" As pointed out in Kang (2013), we suggest that progressives have connotations of dynamism, change, duration, and volition and that volition is one of factors that induce progressives. The reason why the stative verb please has the highest frequency among the three types may be because it has a connotation of volition which the other stative verbs lack. More specifically, we wish to argue that the stative verbs contain and belong have the minus-feature in volition, whereas the stative verb please has the plus-feature in volition, which may enable it to obtain the highest frequency among the three types. From this fact it may be deduced that volition is one of factors that induce progressives. The crucial evidence for this is based on the fact that the same remark applies to semelfactives. Smith (1991), building on Vendler's (1967) system, adds the situation type semelfactive (Semelfactives are instantaneous atelic events (e.g. knock, cough)). How can semelfactives get a connotation of volition? Smith (1991: 224) provides examples of contrasts between simple and progressive forms which show this:

(12)a. She blinked her eyes.

b. She was blinking her eyes.

(Smith 1991: 224)

Smith (1991) maintains that (12b) has a vividness missing from (12a) and that (12b) has a connotation of wilful behavior missing from (12a). It therefore seems reasonable to hypothesize that volition is one of factors that induce progressives and that the reason why the stative verb please obtains the highest frequency among the three types is that it has a connotation of volition which the other stative verbs lack.

Now an important question to be asked here is "what factor triggers the progressive contain and belong?" Note that progressives are durational in that they indicate activity continuing throughout a period of time. The reason why the stative verbs contain and belong can appear in the progressive may be that they have the plus-feature in duration. Note that stative verbs have an overlong steady state, whereas progressives a situation or process which lasts for a period of time. From this, it may be inferred that the stative verbs contain and belong can occur in the progressive so that they can express a situation or process which lasts for a period of time. This is possibly due to the fact that stative verbs have the plus-feature in duration. When it comes to the stative verb please, it has the plus-features in duration, volition, and change, which enables it to obtain the highest frequency among the three types. Now let us turn to the genre frequency of three major sensation verbs used as the progressive.

Table 3 Genre Frequency of Three Major Sensation Verbs Used as the Progressive (COCA)

\begin{tabular}{|l|l|l|l|l|l|l|}
\hline Context & Spoken & Fiction & Magazine & Newspaper & Academic & Total \\
\hline smell & 22 & 29 & 12 & 6 & 3 & 72 \\
\hline taste & 19 & 34 & 12 & 15 & 6 & 86 \\
\hline feel & 1385 & 1735 & 920 & 904 & 300 & 5244 \\
\hline
\end{tabular}

Table 3 shows the use and frequency of the three major sensation verbs which appear in the progressive. A major question which must be addressed here is "which type was the most frequently used one as the progressive in all genres of the three types? The COCA clearly illustrates the fact that the sensation verb feelwasused much more frequently than the other sensation verbs. It is significant to note that just as in the case of stative verbs, sensation verbs which are the symbols of non-progressive verbs can be widely used as the progressive and that the type feel is the most commonly used as the progressive among the three types. One major point of the token analysis of the type smell is that among the five genres, the fiction genre has the highest frequency ( 29 tokens), whereas the academic genre has the lowest frequency (3 tokens). When it comes to the sensation verb taste, on the other hand, just as in the case of the type smell, the fiction genre has the highest frequency (34 tokens), whereas the academic genre has the lowest frequency (6 tokens). Exactly the same can be said about the type feel. Among the five genres, the fiction genre has the highest frequency (1,735 tokens), whereas the academic genre has the lowest frequency (300 tokens). An immediate question to be asked here is "why does the fiction genre of the three sensation verbs have the highest frequency?" Conversely, why does the academic genre of the three sensation verbs have the lowest frequency? We wish to argue that a certain action can become more emotional, intense, and vivid if non-progressive verbs appear in the progressive. It may be reasonable to assume that for this reason, the progressive is the most frequently used in the fiction genre. 
Conversely, the academic genre need not be that way (more emotional, intense, and vivid) since it conveys the truth. Note that the simple present is used to convey the truth. Palmer (1987: 61) stresses that the simple present, not the progressive is used for inductive generalizations and timeless truths. Let us observe the following examples Palmer (1987: 61) provides as an illustration:

(13) a. I always take sugar in tea.

b. The milkman calls on Sundays.

(14) a. Oil floats on water.

b. Water boils at $100 \mathrm{C}$.

(15) a. The Severn flows into Atlantic.

b. The sun rises in the East.

(Palmer 1987: 61)

As alluded to in (13), (14), and (15), the simple present, not the progressive is used to convey inductive generalizations and timeless truths, from which it can be inferred that the progressive is used infrequently in the academic genre.

Now an important question to be asked here is "why does the sensation verb feel (5244 tokens) obtain much higher frequency than the sensation verbs smell (72 tokens) and taste (86 tokens)?" Clearly,progressives are meant to be durational because they have a situation or process which lasts for a period of time. We wish to argue that the sensation verbs smell and taste behave like semelfactives(e.g. knock, cough)which are instantaneous events, so they are not durational. That is, they have the minus-feature in duration. We wish to claim, on the other hand, that as illustrated in (16), the sensation verb feel does not behave like semelfactives and that it has the plusfeature in duration which is supposed to be an important factor that induces progressives:

(16) a. I was feeling guilty.

b. How are you feeling today?

c. Luckily, I was feeling in a good mood.

As exemplified above, (16a), (16b), and (16c) crucially show that the type feelingwhich appears in the progressive is durational since (16a), (16b), and (16c) have similar situations which last for a period of time. Additionally, we wish to claim that the sensation verbs smell and taste have a lower functional load (in the sense of King (1967)) than the sensation verb feel. Simply put, the sensation verb feel is used more frequently than smell and taste in our daily lives. From these two facts it may be deduced that the sensation verb feel has much higher frequency than the other sensation verbs.

Now attention is paid to the frequency of three major mental activity verbs used as the progressive:

Table 4 Genre Frequency of Three Major Mental Activity Verbs Used as the Progressive (COCA)

\begin{tabular}{|l|l|l|l|l|l|l|}
\hline Context & Spoken & Fiction & Magazine & Newspaper & Academic & Total \\
\hline imagine & 3 & 12 & 13 & 0 & 3 & 31 \\
\hline forget & 55 & 66 & 29 & 36 & 11 & 197 \\
\hline believe & 62 & 30 & 58 & 25 & 26 & 201 \\
\hline
\end{tabular}

Noteworthy is that the mental activity verb believe obtains the highest frequency among the three types. More than anything else, the overall frequency of the spoken genre (62 tokens) is higher than that of the fiction (30 tokens) and magazine (58 tokens) genres. What is the reason for this? Cowan (2010) argues that the present progressive seems less binding than the simple present which has the meaning of the truth. Thus, "the use of progressive statives instead of the simple present in expressing requests and wishes can give these a more informal and polite milder tone" (Cowan 2010: 364). As illustrations, his examples are provided here:

(17) a. We are hoping you can explain this mess.

b. We hope you can explain this mess.

(Cowan 2010: 364)

Cowan (2010) further argues that "cognitive stative verbs, such as doubt, remember, and think, in the progressive aspect allow the speaker to hedge, or soften what would otherwise seem more definitive stance" (Cowan 2010: 364). 
According to Cowan (2010: 364), in (18a), the speaker uses a progressive stative in an effort to avoid offending the person addressed and in (18b), a speaker feeling pressured by a somewhat aggressive shoe salesperson wanted to politely reject his suggestion:

(18) a. Mind you, I'm not doubting your word, but I did get a different version of what happened from Peter.

b. No, I'm sort of thinking that I'd like to try a bit higher level heel, anyway.

(Cowan 2010: 364)

Consequently, mental activity verbs which appear in the progressive provide an informal polite tone and hedge or soften a definitive opinion. This observation thus confirms the prediction that the spoken genre of believe can obtain the highest frequency among the five genres.

One major point of imagine is that among the five genres, the magazine genre has the highest frequency (13 tokens), whereas the newspaper genre has the lowest frequency (0 token). A further point to note is that the fiction genre of the type forget has the highest frequency among the five genres, whereas the academic genre of the type forget has the lowest frequency among the five genres. An immediate question to be asked here is "why does the fiction genre of the type forget have the highest frequency?" Conversely, why does the academic genre of the type forget have the lowest frequency? It is interesting to note that the sensation verbs smell, taste, and feel and the mental activity verb forget show the same pattern with respect to the frequency of the fiction and academic genres. It should be noted again that a certain action can become more emotional, intense, and vivid if nonprogressive verbs appear in the progressive. This action may coincide with writers' strategy in novels since one of writers' strategies in novels is to make a certain action become more emotional, intense and vivid. Therefore, it may be reasonable to assume that for this reason, the fiction genre of the type forget is the most frequently used among the five genres. Conversely, the academic genre is different from the fiction genre in that it conveys the truth. As observed earlier, the simple present, not the progressive is used to convey inductive generalizations and timeless truths, which we take as indicating that the progressive is used infrequently in the academic genre. This in turn suggests that the academic genre of the mental activity verb forget can obtain the lowest frequency among the five genres.

Finally, it is important to note that the overall frequency of the three types of non-progressive verbs shows the effect of the following hierarchy:

(19) sensation verbs > mental activity verbs > stative verbs

As illustrated in Table 1, Table 3, and Table 4, the COCA (1990-2012) clearly shows that the sensation verbs as the progressive are the most preferred type for American people, followed by the mental activity verbs, and the stative verbs, in that order. This observation leads to the assumption that sensation verbs among the three types of non-progressive verbs are the most frequently used type by American people.

\subsection{A Frequency Analysis of Non-progressive Verbs (BNC)}

As pointed out in Biber (1995), people who use the same language in different regions and countries may talk differently. Now attention is paid to the Corpus of Contemporary American English(1990-2012)and the British National Corpus(from the 1980s to the early 1990s) to examine the national variation of the three types of nonprogressive verbs. Table 5 shows the use and genre frequency of the three major stative verbs:

Table 5 Genre Frequency of Three Major Stative Verbs Used as the Progressive (BNC: from the 1980s to the early 1990s)

\begin{tabular}{|l|l|l|l|l|l|l|l|l|}
\hline Context & Spoken & Fiction & Magazine & Newspaper & $\begin{array}{l}\text { Non- } \\
\text { Acad }\end{array}$ & Academic & Misc & Total \\
\hline contain & 1 & 0 & 0 & 0 & 1 & 0 & 1 & 3 \\
\hline belong & 1 & 1 & 0 & 0 & 0 & 0 & 0 & 2 \\
\hline please & 3 & 12 & 8 & 4 & 4 & 3 & 18 & 52 \\
\hline
\end{tabular}

One characteristic of the token analysis of the stative verbs contain, belong, and please is that contain and belong as the progressive are used infrequently in the seven genres, whereas please as the progressive is used much more frequently than the other stative verbs. This raises the question of why contain and belongwere used infrequently. Conversely, why was the stative verb please used much more frequently than the other stative verbs? 
We wish to argue that language is the vehicle of thought and that American people are emotional people in that they want a certain action to become more emotional, intense and vivid in both spoken and fiction genres. On the other hand, British people are more or less conservative in their use of progressive statives in view of the fact that they use fewer progressive statives than American people. Then, why is the type please used much more frequently than the other stative verbs? The reason why the stative verb pleasewas used much more frequently than the other stative verbs is that it has a connotation of volition which the other stative verbs lack. As observed earlier, we wish to claim that the stative verbs contain and belong have the minus-feature in volition, whereas the stative verb please has the plus-feature in volition, which may result in the highest frequency among the three types. As evidenced by both COCA and BNC (Table 1 and Table 5), the fact that the stative verb please was used much more frequently than the other stative verbs provides further confirmation that volition is one of factors that induce progressives.

It is interesting to point out that the misc genre of the type please was the most frequently used among the seven genres. The spoken and academic genres of please were used infrequently, compared to the other genres. It should be noted that the overall frequency of the fiction genre is 12 tokens and accounts for $23 \%$ of the total use of the type please. The reason why the frequency of the fiction genre is higher than that of the other genres is that just as in the case of the COCA, writers in novels may use the strategy that a certain action can become more emotional, intense, and vivid. It may be therefore reasonable to assume that the fiction genre obtains higher frequency than the other genres. Conversely, the academic genre is different from the fiction genre in that it conveys the truth. Thus, the simple present in the academic genre is used much more frequently than the progressive, which results in the lower frequency of the progressive. We are now ready to turn our attention to the three major sensation verbs in the BNC.

Table 6 Genre Frequency of Three Major Sensation Verbs Used as the Progressive (BNC)

\begin{tabular}{|l|l|l|l|l|l|l|l|l|}
\hline Context & Spoken & Fiction & Magazine & Newspaper & $\begin{array}{l}\text { Non- } \\
\text { academic }\end{array}$ & Academic & Misc & Total \\
\hline smell & 0 & 5 & 0 & 0 & 0 & 0 & 0 & 5 \\
\hline taste & 0 & 1 & 1 & 0 & 2 & 0 & 1 & 5 \\
\hline feel & 47 & 390 & 44 & 86 & 81 & 26 & 145 & 819 \\
\hline
\end{tabular}

An important question to be asked here is "which type is the most commonly used one as the progressive in all genres of the three types?" The BNC clearly illustrates that just as in the case of the COCA, the type feel is the most widely used among the three types. It is worthwhile noting that feelwhich is one of non-progressive verbs was used much more frequently than the other types, whereas the sensation verbs smell and taste as the progressive are used infrequently. An immediate question to be asked here is "why was the sensation verb feel used much more frequently than the other sensation verbs?" One of the reasons why the sensation verb feel is used much more frequently than the other types may be that it has a connotation of duration which the other sensation verbs lack. As observed earlier, progressives have a situation or process which lasts for a period of time. Further supporting evidence in favor of our analysis comes from Palmer's (1987: 74) claim that the sensation verb hear can occur in the progressive where there is emphasis upon the duration:

(20) I'm actually hearing your voice!

(Palmer 1987: 74)

According to Palmer (1987: 74), the sensation verb hear can appear in the progressive where there are repetitions of the sensation for a period of time and in this case, these sensations are imaginary or hallucinatory. From this it can reasonably be concluded that duration is one of factors which induce progressives.

A major question that must be addressed here is "which genre(s) can be influenced mainly by the use of a certain sensation verb?" Noteworthy is that the fiction genre in the case of smell and feel is preferred to the other genres and that it is influenced mainly by the use of smell and feel. On the other hand, it is significant to note that the academic genre of the three types is scarcely influenced by the use of the three types. What is the reason for this? Again, we emphasize that the progressive is used more frequently in the fiction genre since writers tend to use the strategy that a certain action can be more emotional, intense, and vivid, whereas the simple present is used much more frequently than the progressive in the academic genre since the academic genre conveys the truth. 
We now turn our attention to the three major mental activity verbs used as the progressive in the BNC.

Table 7 Genre Frequency of the Three Major Mental Activity Verbs Used as the Progressive (BNC)

\begin{tabular}{|l|l|l|l|l|l|l|l|l|}
\hline Context & Spoken & Fiction & Magazine & Newspaper & $\begin{array}{l}\text { Non- } \\
\text { academic }\end{array}$ & Academic & Misc & Total \\
\hline imagine & 4 & 30 & 1 & 2 & 1 & 1 & 3 & 42 \\
\hline forget & 4 & 29 & 0 & 4 & 3 & 1 & 7 & 48 \\
\hline believe & 1 & 1 & 0 & 2 & 0 & 1 & 9 & 14 \\
\hline
\end{tabular}

It is worth noting that in the COCA, mental activity verbs mainly occur in the progressive to provide an informal polite tone and to hedge or soften a definitive opinion. Simply put, the spoken and fiction genres in the COCA are influenced mainly by the use of the types forget and believe. In the BNC, however, the fiction genre rather than the spoken genre is influenced mainly by the use of the types imagine (42 tokens) and forget (48 tokens). This in turn indicates that American people prefer polite expressions and positive euphemisms in both spoken and fiction genres, whereas British people prefer them in the fiction genre rather than in the spoken genre. It is no wonder the progressive is much used in the fiction genre because of writers' strategy that a certain action can be more emotional, intense, and vivid.

Finally, it must be noted that the overall frequency of the three types of non-progressive verbs shows the effect of the following hierarchy:

(21) sensation verbs $>$ mental activity verbs $>$ stative verbs

The BNC clearly indicates that just as in the case of the COCA, the sensation verbs as the progressive are the most preferred type for British people, followed by the mental activity verbs, and the stative verbs, in that order. It is therefore reasonable to assume that the sensation verbs among the three types are the most widely used type as the progressive by both American and British people.

\subsection{A Frequency Analysis of Non-progressive Verbs (COHA)}

Let us now turn to the frequency of the stative verbs, sensation verbs, and mental activity verbs in the COHA:

Table 8 Frequency of Non-Progressive Verbs Used as the Progressive (COHA)

\begin{tabular}{|l|l|l|l|l|l|l|l|l|l|}
\hline Types & Stative Verbs & \multicolumn{3}{l}{ Sensation Verbs } & \multicolumn{3}{l|}{ Mental Activity Verbs } \\
\hline Year & contain & belong & please & smell & taste & feel & imagine & believe & forget \\
\hline 1810 & 0 & 0 & 2 & 0 & 0 & 1 & 0 & 0 & 0 \\
\hline 1820 & 0 & 0 & 17 & 0 & 1 & 3 & 0 & 6 & 0 \\
\hline 1830 & 0 & 0 & 34 & 0 & 0 & 11 & 1 & 5 & 1 \\
\hline 1840 & 0 & 0 & 34 & 2 & 2 & 12 & 0 & 3 & 3 \\
\hline 1850 & 0 & 0 & 30 & 0 & 1 & 16 & 1 & 3 & 5 \\
\hline 1860 & 0 & 1 & 24 & 1 & 1 & 26 & 1 & 5 & 10 \\
\hline 1870 & 0 & 1 & 17 & 3 & 0 & 45 & 5 & 4 & 12 \\
\hline 1880 & 0 & 0 & 29 & 1 & 1 & 56 & 2 & 8 & 20 \\
\hline 1890 & 0 & 0 & 14 & 0 & 1 & 98 & 4 & 4 & 9 \\
\hline 1900 & 0 & 0 & 23 & 1 & 6 & 109 & 4 & 5 & 30 \\
\hline 1910 & 0 & 0 & 22 & 3 & 2 & 139 & 2 & 4 & 30 \\
\hline 1920 & 0 & 0 & 30 & 1 & 5 & 129 & 6 & 8 & 32 \\
\hline 1930 & 0 & 0 & 17 & 2 & 7 & 202 & 2 & 5 & 18 \\
\hline 1940 & 0 & 0 & 16 & 4 & 7 & 202 & 4 & 5 & 12 \\
\hline 1950 & 0 & 0 & 14 & 3 & 1 & 183 & 5 & 8 & 13 \\
\hline 1960 & 1 & 0 & 11 & 8 & 5 & 212 & 5 & 3 & 5 \\
\hline 1970 & 0 & 1 & 15 & 6 & 4 & 216 & 18 & 1 & 13 \\
\hline 1980 & 1 & 0 & 5 & 4 & 4 & 244 & 22 & 5 & 10 \\
\hline 1990 & 1 & 0 & 9 & 7 & 7 & 338 & 28 & 4 & 11 \\
\hline 2000 & 0 & 1 & 5 & 6 & 4 & 386 & 25 & 5 & 13 \\
\hline Total & 3 & 4 & 368 & 52 & 59 & 2,628 & 135 & 91 & 247 \\
\hline
\end{tabular}


It is worth noting that the type feel as the progressive was the most preferred by American people among the nine non-progressive verbs for one hundred and ninety years from 1810 to 2000. Table 8 crucially shows that among the nine non-progressive verbs the most preferable type for speakers and writers in America is the type feel since it has the highest frequency $(2,628$ tokens) and the highest proportion $(73.26 \%)$. Why does the sensation verb feel have the highest frequency and the highest proportion among the nine non-progressive verbs? We suggest that progressives have connotations of dynamism, change, duration, and volition and that dynamism, change, duration, and volition are factors which induce progressives. The reason why the sensation verb feel obtains the highest frequency among the nine non-progressive verbs may be that it has the plus-features in volition, duration, and change even though it seems to have the minus-feature in dynamism:

(22) a. Feeling better?

b. I am feeling guilty.

c. Luckily, I was feeling in a good mood.

These examples are intended to suggest that the sensation verb feel has connotations of change, duration, and volition which may trigger progressives. On the other hand, the stative verbs contain and belong have the plusfeature in only duration but the minus-features in change, dynamism, and volition, which may result in the extremely low frequency. Then why is the stative verb please used much more frequently than the other stative verbs? Why was forget used more frequently than the sensation verbs smell and taste? The reason why the stative verb please was used much more frequently than contain and belong may be that the type please has the plusfeatures in duration, change, and volition, whereas contain and belong have the plus-feature in only duration. Similarly, the reason why the type forget is used more frequently than smell and taste may be that forget has the plus-features in volition, duration, and change, whereas smell and taste have the plus-features in volition and dynamism. These results are predicted, given the hypothesis that progressives have connotations of duration, volition, change, and dynamism and that they are factors which trigger progressives.

As can be seen from Table 8, one crucial point of the type please is that its figure continued to increase to 34 tokens for 30 years from 1810 to 1840 and reached the peak in the 1830s and 1840s. After this period, there was a steady reduction in the figure from 1850 to 1870 and then there were slight fluctuations in the figure of the type please. Another point to note is that there was a steady decline in the figure from 1930 to 1960 and then there was a marked decrease in the figure from 1980 (5 tokens) to 2000 (5 tokens), which in turn suggests that the type please as the progressive was not preferred by American people in the 2000s.

Now we turn our attention to the use and frequency of the type feel from 1810 to 2000 . When it comes to the type feel, there was a dramatic rise in its figure for 100 years from 1810 to 1910 and it was ranked first among the nine non-progressive verbs from 1860 to 2000 . After this period, there were slight fluctuations in the figure and then there was a marked increase in the figure from 1950 to 2000. It is important to note that the figure of feel reached the peak in the 2000s and it was ranked first among the nine non-progressive verbs from 1860 to 2000, which in turn suggests that the type feel was the most preferred by American people from 1860 to 2000. As for the type forget, there was steady rise in its figure from 1810 to 1880 and there were slight fluctuations in its frequency from 1880 to 1900. After this period, its figure reached the peak in the 1920s (32 tokens) and then there was a steady decline from 1920 to 2000, which implies that the type forget as the progressive was the most preferred by American people in the 1920s.

\subsection{A Frequency Analysis of Non-progressive Verbs (TMC)}

In what follows, we briefly examine the use and frequency of the nine non-progressive verbs in the TMC.

Table 9 Frequency of Non-Progressive Verbs Used as the Progressive (TMC)

\begin{tabular}{|c|c|c|c|c|c|c|c|c|c|}
\hline \multirow{2}{*}{$\begin{array}{l}\text { Types } \\
\text { Year }\end{array}$} & \multicolumn{3}{|c|}{ Stative Verbs } & \multicolumn{3}{|c|}{ Sensation Verbs } & \multicolumn{3}{|c|}{ Mental Activity Verbs } \\
\hline & contain & belong & please & smell & taste & feel & imagine & believe & forget \\
\hline $1920 \mathrm{~s}$ & 0 & 0 & 7 & 0 & 2 & 20 & 1 & 1 & 1 \\
\hline $1930 \mathrm{~s}$ & 0 & 0 & 6 & 0 & 0 & 44 & 0 & 1 & 1 \\
\hline $1940 \mathrm{~s}$ & 0 & 0 & 6 & 2 & 2 & 100 & 0 & 2 & 2 \\
\hline $1950 \mathrm{~s}$ & 0 & 0 & 7 & 1 & 1 & 73 & 1 & 2 & 7 \\
\hline $1960 \mathrm{~s}$ & 1 & 0 & 6 & 0 & 0 & 68 & 2 & 1 & 2 \\
\hline $1970 \mathrm{~s}$ & 0 & 0 & 3 & 0 & 0 & 38 & 0 & 2 & 2 \\
\hline $1980 \mathrm{~s}$ & 0 & 0 & 8 & 0 & 0 & 45 & 1 & 5 & 6 \\
\hline $1990 \mathrm{~s}$ & 0 & 0 & 1 & 3 & 1 & 65 & 0 & 5 & 3 \\
\hline $2000 \mathrm{~s}$ & 0 & 0 & 0 & 1 & 0 & 59 & 3 & 0 & 3 \\
\hline Total & 1 & 0 & 44 & 7 & 6 & 512 & 8 & 19 & 27 \\
\hline
\end{tabular}


An important question to be asked here is "which type was the most preferable one for educated American people for 80 years?" Table 9 crucially shows that the most preferable type for educated American people among the nine non-progressive verbs from the 1920 s to the 2000 s was the type feel. Among the three types of nonprogressive verbs, the sensation verbs were the most preferred by educated American people, followed by the mental activity verbs, and the stative verbs, in that order. Among the stative verbs, the type please has the highest frequency (44 tokens), among the sensation verbs, the type feel has the highest frequency (512 tokens), and among the mental activity verbs, the type forget has the highest frequency (27 tokens), which in turn suggests that the results of the TMC pattern with those of the BNC and COHA, not with those of the COCA. It is significant to note that the stative verb contain, the sensation verbs small and taste, and the mental activity verb imagine were used infrequently as the progressive for 80 years. This implies that the behavior of educated American people in the use of the progressive patterns with that of British people. It is worth emphasizing, however, that feel, please, and forget were used much more frequently than the other non-progressive verbs. One of the reasons may be because they are used much more frequently than the other non-progressive verbs in our daily lives. Another reason may be that feel, please, forget have the plus-features in duration, change, and volition in common. This, again, is predicted, given the hypothesis that progressives have connotations of duration, volition, change, and dynamism and that they are factors which trigger progressives.

Now we turn to the use and frequency of the sensation verb feel. It is worth pointing out that there was a dramatic increase in the number of the token of feel for twenty years from the 1920s to the 1940s. In fact, there was a rise of 80 tokens from the 1920s to the 1940s. After this period, there was a sudden decrease in the number of the token of the type feel for thirty years from the 1950s to the 1980s and then there were slight fluctuations in the figure of feel from the 1980s to the 2000s. It must be noted that the figure of feel reached the peak in the 1940s and then continued to decrease, which suggests that the type feel was the most preferred by educated American people in the 1940s.

Finally, it is worthwhile noting that the stative verb belong was never used by educated American people for eighty years from the 1920 s to the 2000s. The main reason why belong was never used by educated American people may be that belong has the minus-features in change, volition, and dynamism which trigger progressives, which may lead to no frequency.

\section{Conclusion}

The main goal of our research is to provide a frequency analysis of major stative verbs, major sensation verbs, and major mental activity verbs within the systems of the COCA, BNC, COHA, and TMC and to provide clues as to why non-progressive verbs occur in the progressive and why they show differences in the use of the progressive. In section 2 and section 3, we have provided background discussion for the remainder of this article. In section 4.1, we have provided a frequency analysis of major stative verbs, major sensation verbs, and major mental activity verbs which occur in the progressive in the COCA. We have pointed out that there are several reasons why non-progressive verbs occur in the progressive. We have argued in this section that the reason why the stative verb please has the highest frequency among contain, belong, and please may be because it has a connotation of volition which the other statives lack.

We have further argued that the reason why feel obtains the highest frequency among smell, taste, and feel is that smell and taste have the minus-feature in duration, whereas feel has the plus-feature in duration which is supposed to be an important factor that induces progressives. Section 4.2 was devoted to analyzing the frequency of major stative verbs, major sensation verbs, and mental activity verbs used as the progressive in the BNC. We have argued that language is the vehicle of thought and that American people are emotional people in that they want a certain action to become more emotional, intense and vivid in both spoken and fiction genres. Also, we have maintained that the reason why the frequency of the fiction genre in the BNC is higher than that of the other genres is that just as in the case of the COCA, writers in novels may use the strategy that a certain action can become more emotional, intense, and vivid. It must be noted that one of the reasons why the sensation verb feel is used much more frequently than smell and taste may be that it has a connotation of duration which smell and taste lack. In this section, we have argued that mental activity verbs mainly occur in the progressive to provide an informal polite tone and to hedge or soften a definitive opinion. In section 4.3, our discussion was devoted on analyzing the frequency of nine non-progressive verbs which occur in the progressive in the $\mathrm{COHA}$. 
In this section, we have contended that the sensation verb feel has connotations of change, duration, and volition which may trigger the progressive, whereas the stative verbs contain and belong have the plus-feature in only duration but the minus-features in change, dynamism, and volition, which may result in the extremely low frequency. Similarly, we have maintained that the reason why the type forget is used more frequently than smell and taste may be that forget has the plus-features in volition, duration, and change, whereas smell and taste have the plus-features in volition and dynamism. In section 4.4 , we have provided a frequency analysis of nine nonprogressive verbs used as the progressive in the TMC. We have argued that the most preferable type for educated American people among the nine non-progressive verbs from the 1920 s to the 2000s was the type feel. We have further argued that among the three types of non-progressive verbs, the sensation verbs were the most preferred by educated American people, followed by the mental activity verbs, and the stative verbs, in that order.

\section{References}

Biber, D. (1995). On the role of computational, statistical, and interpretive techniques in multi-dimensional analysis of register variation. Text 15 (3): 314-370.

British National Corpus (BNC).https://corpus.byu.edu/bnc.

Corpus of Contemporary American English (COCA). https://corpus.byu.edu/coca.

Corpus of Historical American English (COHA). https://corpus.byu.edu/coha.

Cotos, E. (2017). Language for specific purposes and corpus-based pedagogy.InThe handbook of technology and second language teaching and learning.edited by Carol A. Chapelle and Shannon Sauro, 248-264. Wiley Blackwell.

Cowan, R. (2010). The teacher's grammar of English. Cambridge: Cambridge University Press.

Kang, N-K.(2013). Four factors that induce progressives.Studies in Linguistics 27: 1-24.

King, R. D. (1967). Functional Load and Sound Change.Language 43: 831-852.

Palmer, F. R. (1987). The English verb. New York: Longman Publishers.

Quirk, R. and Greenbaum, S. (1993). University grammar of English.Longman.

Saeed, J. (2009). Semantics. Oxford. Blackwell Publishers.

Time Magazine Corpus (TMC). https://corpus.byu.edu/time.

Twaddell, W. F. (1965). The English verb auxiliaries ( ${ }^{\text {nd }}$ edition). Providence: Brown University Press.

Vlach, F. (1981).The semantics of the progressive. In Philip Tedeschi and Annie Zaenen (eds.) Syntax and semantics 14: Tense and Aspect: 271-292. New York: Academic Press. 